INTERSTITIAL LUNG DISEASE

\title{
Exhaled nitric oxide in sarcoidosis
}

\author{
M L Wilsher, W Fergusson, D Milne, A U Wells
}

Thorax 2005;60:967-970. doi: 10.1136/thx.2004.033852

See end of article for authors' affiliations

authors affiliations

Correspondence to: Dr M L Wilsher, Green Lane Respiratory Services, Auckland City Hospital, Auckland 1, New Zealand; mwilsher@adhb.govt.nz

Received 29 August 2004 Accepted 25 August 2005

\begin{abstract}
Background: Increased production of nitric oxide (NO) by the lower respiratory tract is viewed as a marker of airway inflammation in asthma and bronchiectasis. NO is a potentially important immune modulator, inhibiting the release of several key pro-inflammatory cytokines. As sarcoidosis is characterised by granulomatous airway inflammation, we hypothesised that exhaled NO levels might be raised in sarcoidosis and correlate with the morphological extent and functional severity of disease. Methods: Fiffy two patients with sarcoidosis (29 men) of mean age 42 years underwent thin section computed tomography (CT), pulmonary function tests, and measurement of exhaled NO.

Results: Exhaled NO levels (median $6.8 \mathrm{ppb}$, range 2.4-21.8) did not differ significantly from values in 44 control subjects, and were not related to the extent of individual CT abnormalities or the level of pulmonary function impairment.

Conclusion: Exhaled NO levels are not increased in pulmonary sarcoidosis.
\end{abstract}

S arcoidosis is a multisystem granulomatous disorder characterised by the accumulation of activated $\mathrm{T}$ lymphocytes releasing the $\mathrm{T}$ helper $\mathrm{l}$ (Thl) cytokines interleukin (IL)-2 and interferon $\gamma$ at sites of inflammation and granuloma formation. ${ }^{1}$ The disease is believed to result from IL-12 dysregulation, with perpetuation of a Thl response to an irrelevant antigen, although another cytokine (IL-18) is also implicated in the pathogenesis. ${ }^{2}$

Nitric oxide (NO) is a regulator of many biological functions including Thl and Th2 balance, ${ }^{3}$ and has many roles in cell signalling and host defence. It is involved in the killing or inhibition of pathogens associated with Thl type immune responses such as Mycobacterium tuberculosis. ${ }^{4}$ Exhaled NO (eNO) levels, a marker of NO production in the respiratory tract, correlate with airway inflammation, especially in asthma. ${ }^{5}$ As NO may have anti-inflammatory and pro-inflammatory effects and sarcoidosis is characterised by granulomatous airway inflammation, we hypothesised that eNO levels would be increased in this disease and would correlate with disease severity, as judged by lung function tests and HRCT scanning.

Exhaled NO levels have been reported in only two studies of patients with sarcoidosis and these have shown conflicting results. O'Donnell et al showed that eNO was not increased in 10 patients with sarcoidosis but, in contrast, Moodley et al ${ }^{8}$ reported the opposite in a cohort of 12 patients. Neither study correlated the eNO levels with HRCT appearances or detailed lung function testing, although Moodley et al did use forced expiratory volume in 1 second $\left(\mathrm{FEV}_{1}\right)$ measurements. In this study we have examined eNO in a cohort of 52 patients with sarcoidosis, correlating levels with detailed lung function testing and HRCT.

\section{METHODS \\ Subjects}

The study subjects comprised 52 patients (29 men) of mean age 42 years (range 23-66) with sarcoidosis diagnosed on the basis of typical histology or unequivocal HRCT findings in association with typical clinical features. All patients were from the Auckland region and came from a range of ethnic groups (41 white, 5 Indian, 4 Polynesian, 1 Asian, 1 African). Seven patients were current smokers and there were five exsmokers. No patient was on treatment (oral or inhaled) at the time of the study or in the preceding 3 months. Fifteen patients had the eNO measurements made at initial presentation and 37 during follow up as part of routine lung function testing. Chest radiographic abnormalities were as follows: Stilback stage 0: 3; stage I: 13; stage II: 21; stage III: 14; stage IV: 1. Fifteen patients $(29 \%)$ had extrapulmonary manifestations of their disease at some stage during their illness. Thirty one patients also had assessment of atopy, defined as one or more positive serum RAST responses to four common aeroallergens, as part of another study. The data were compared with those from 44 normal non-smoking volunteers recruited as part of an earlier study. ${ }^{9}$

The determination of eNO levels in normal volunteers and the measurement of serum RAST in all subjects was performed with the approval of the Northern Regional Ethics Committee, Auckland, New Zealand.

\section{Exhaled nitric oxide measurements}

Nitric oxide was measured with a modified chemiluminescence analyser (model LR2000; Logan Research, Rochester, UK) sensitive to NO from 1 to $5000 \mathrm{ppb}$ (by volume), and a resolution of $1 \mathrm{ppb}$ which had been designed for online recording of the eNO concentration. In addition to $\mathrm{NO}$, the analyser also measured $\mathrm{CO}_{2}$ (resolution of $0.1 \%, \mathrm{CO}_{2}$ response time of $200 \mathrm{~ms}$ ). When not in use the system sampled charcoal scrubbed air which was free of NO and the machine was not exposed to ambient air. Calibration was checked weekly using a standard gas at $100 \mathrm{ppb}$ NO. All measurements were undertaken at ambient NO levels of $<20 \mathrm{ppb}$.

Subjects were studied in the sitting position. Exhaled NO was measured during slow exhalation from total lung capacity to residual volume. The exhalation flow rate was $15 \mathrm{l} / \mathrm{min}$ and was kept as constant as possible by using a biofeedback visual display. Expired air was sampled via a side arm tube (at $250 \mathrm{ml} / \mathrm{min}$ ) directly into the analyser for $\mathrm{NO}$ measurement. The plateau level of the last part of exhalation when $\mathrm{CO}_{2}$ was $70-80 \%$ of maximum was taken as the eNO concentration.

\footnotetext{
Abbreviations: eNO, exhaled nitric oxide; $\mathrm{FEF}_{25-75}$, mean forced expiratory flow during middle half of $\mathrm{FVC} ; \mathrm{FEV}_{1}$, forced expiratory volume in 1 second; FVC, forced vital capacity, FRC, functional residual capacity; RV, residual volume, TLC, total lung capacity, TLCO, carbon monoxide lung transfer factor
} 
To measure nasal NO a wide bore Teflon coated catheter was placed in the nares (front of nose) and a sample aspirated at $500 \mathrm{ml} / \mathrm{min}$ during breath holding at the end of inspiration. The plateau NO level was taken as the level of nasal NO. Continued soft palate closure was confirmed by the absence of an increase in $\mathrm{CO}_{2}$ during sampling. Measurements of NO were performed with no technician awareness of previous recordings.

Data from our laboratory have shown a coefficient of variation of $12.7 \%$ derived from the single determination standard deviation of measurements taken on separate days. ${ }^{9}$

\section{Lung function measurement}

The following lung function measurements (lung volumes and flow measurements) were undertaken in the Lung Function Laboratory at Green Lane Hospital according to American Thoracic Society (ATS) standards ${ }^{10}$ by a qualified technician using a 6200 Autobox DL (Sensormedics, Yorba Linda, USA): $\mathrm{FEV}_{1}$, forced vital capacity (FVC), functional residual capacity (FRC), residual volume (RV), total lung capacity (TLC), mean forced expiratory flow during the middle half of the FVC ( $\left.\mathrm{FEF}_{25-75}\right)$ and carbon monoxide lung transfer factor (TLCO). The European Community Coal and Steel recommendations ${ }^{11}$ were used as reference normal values. All measurements were undertaken on the same day as the eNO measurement and within a month of the CT scan.

\section{CT scanning}

Thin section CT studies were performed using a General Electric Prospeed Advantage CT scanner. One millimetre collimation scans were performed at $10 \mathrm{~mm}$ intervals at full inspiration. Limited further interspaced sections were performed at end expiration. The CT scans were assessed in random order by two independent experienced observers (DM and AUW) without knowledge of clinical findings or lung function tests. The extent of individual CT patterns was estimated in each lobe as follows: grade $1=\leqslant 25 \%$ of the lobe; grade $2=26-50 \%$ of the lobe; grade $3=51-75 \%$ of the lobe; grade $4=>75 \%$ of the lobe. CT patterns quantified in this way were: (1) mosaic attenuation (scored using expiratory images); (2) ground glass opacification; (3) nodules up to $8 \mathrm{~mm}$ in diameter; (4) consolidation; and (5) a reticular pattern (interlacing linear opacities, including thickened interlobular septa) or honeycombing. The total extent of each pattern in each patient was determined by adding the scores in the six lobes, providing a 25 point scale (0-24). Bronchial wall thickening and bronchiectasis were also quantified using a four point scale $(0-3)$ in each lobe,

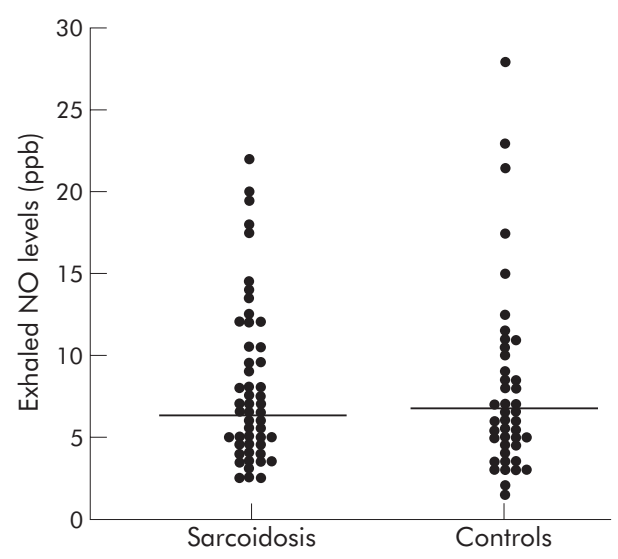

Figure 1 Exhaled nitric oxide levels in 52 patients with sarcoidosis and 44 normal non-smoking controls.

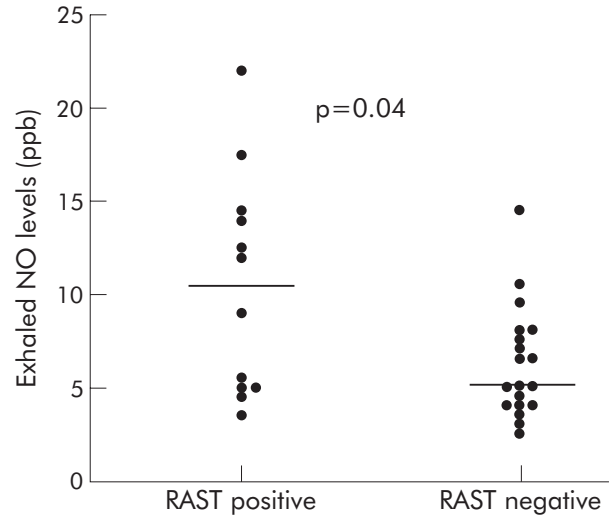

Figure 2 Exhaled nitric oxide levels in 12 atopic and 19 non-atopic patients with sarcoidosis.

and thus a 19 point scale $(0-18) .{ }^{12}$ The summed scores of the two observers were used for the analysis.

\section{Statistical analysis}

Group data were expressed as mean (SD) values or median (range) values for non-normally distributed variables. Univariate correlations between functional indices and eNO levels and between CT patterns and eNO levels were examined using Spearman rank correlation test (STATA data analysis software; Computing Resource Center, Santa Monica, CA, USA). Comparisons of paired data were made using the Wilcoxon's rank sum test. Multivariate relationships between (1) individual lung function indices and CT scores and (2) eNO levels and CT scores were examined using stepwise linear regression. Individual functional indices and eNO were evaluated as dependent variables in separate models. Covariates consisted of the CT scores listed in table 1 (with the exception of bronchiectasis scores, positive in only eight patients). All models satisfied the parametric assumptions of multiple linear regression as judged by testing for heterscedasticity.

\section{RESULTS}

As shown in fig 1, eNO levels (median 6.8 ppb, range 2.421.8 ) did not differ significantly from eNO levels in 44 normal subjects (median $6.3 \mathrm{ppb}$, range 1.6-28.0). There was no correlation between eNO levels and the duration of disease (time since diagnosis). There was a trend to higher eNO levels in the 12 atopic patients (median eNO 10.7 ppb (range 3.421.8 ), fig 2). There was no correlation between eNO levels and total serum $\operatorname{IgE}(r=-0.12, \mathrm{p}=0.53)$.

Pulmonary function abnormalities, expressed as mean (SD) percentages of normal predicted values, varied from severe obstruction to restriction, with neither predominating overall $\left(\mathrm{FEV}_{1} 87.9\right.$ (18.5); FVC 93.7 (16.1); $\mathrm{FEF}_{25-75} 64.1$

\begin{tabular}{ll}
$\begin{array}{l}\text { Table } 1 \text { Prevalence of CT abnormalities in } 52 \\
\text { patients with sarcoidosis }\end{array}$ \\
\hline & $\begin{array}{l}\text { Median (range) } \\
\text { CT score }\end{array}$ \\
\hline Nodules $(n=42)$ & $10(2-27)$ \\
Reticular abnormalities $(n=37)$ & $6(2-30)$ \\
Consolidation $(n=30)$ & $6(2-18)$ \\
Ground glass attenuation $(n=25)$ & $2(2-38)$ \\
Mosaic attenuation $(n=45)$ & $10(2-24)$ \\
Bronchial wall thickness $(n=29)$ & $6(2-14)$ \\
Bronchiectasis $(n=8)$ & $3(2-11)$ \\
\hline & \\
\hline
\end{tabular}


Table 2 Most powerful functional morphological univariate relationships (expressed as Spearman rank correlation coefficients) between pulmonary function indices and CT scores

\begin{tabular}{llll}
\hline & Reticular score & Consolidation score & Mosaic attenuation score \\
\hline $\mathrm{FEV}_{1}(\%$ predicted) & $R=-0.59(\mathrm{p}<0.0005)$ & $R=-0.61(\mathrm{p}<0.0005)$ & $R=-0.37(\mathrm{p}<0.01)$ \\
$\mathrm{FEF}_{25-75}(\%$ predicted $)$ & $R=-0.61(\mathrm{p}<0.0005)$ & $R=-0.58(\mathrm{p}<0.0005)$ & $R=-0.47(\mathrm{p}<0.0005)$ \\
\hline
\end{tabular}

Increasing reticular abnormalities, consolidation, and mosaic attenuation were all associated with reductions in $\mathrm{FEV}_{1}$ and $\mathrm{FEF}_{25-75}$.

(25.0); TLC 97.7 (13.3); RV 91.7 (26.1); TLCO 85.5 (18.9); KCO 104.5 (18.4)). The prevalence of individual CT abnormalities and the median CT scores with ranges are shown in table 1.

Before examination of the relationship between eNO levels and disease severity, key functional morphological relationships were identified. The strongest univariate associations, all involving $\mathrm{FEV}_{1}$ or $\mathrm{FEF}_{25-75}$, are shown in table 2.

On stepwise regression, the percentage predicted $\mathrm{FEF}_{25-75}$ $\left(R^{2}=0.62\right)$ and $\operatorname{FEV}_{1}\left(R^{2}=0.56\right)$ were much more closely related to morphological abnormalities than other functional variables (TLCO, $R^{2}=0.29 ; \mathrm{FVC}, R^{2}=0.27$; other variables, $\left.R^{2}<0.20\right)$. Reductions in $\mathrm{FEF}_{25-75}$ were independently associated with increasing reticular abnormalities (regression coefficient $(\mathrm{RC})=-1.09$; 95\% confidence interval $(\mathrm{CI})-1.81$ to $-0.36 ; \mathrm{p}=0.003)$, consolidation $(\mathrm{RC}=-2.10 ; 95 \% \mathrm{CI}$ -3.22 to $-0.97 ; \mathrm{p}<0.001)$, mosaic attenuation $(\mathrm{RC}=-1.39$; $95 \%$ CI -2.16 to $-0.63 ; \mathrm{p}<0.001)$, and bronchial wall thickness $(\mathrm{RC}=-2.09 ; 95 \% \mathrm{CI}-3.33$ to $-0.84 ; \mathrm{p}<0.001)$. Reductions in $\mathrm{FEV}_{1}$ were independently associated with increasing reticular abnormalities $(\mathrm{RC}=-0.90 ; 95 \%$ CI -1.46 to $-0.33 ; \mathrm{p}=0.002)$, consolidation $(\mathrm{RC}=-1.25 ; 95 \%$ CI -2.06 to $-0.43 ; \mathrm{p}=0.002)$, and mosaic attenuation $(\mathrm{RC}=-0.89 ; 95 \% \mathrm{CI}-1.49$ to $-0.28 ; \mathrm{p}=0.004)$.

On univariate analysis, eNO levels were not linked to individual pulmonary function variables or CT scores. On stepwise regression, no independent relationships were found between eNO levels and individual CT scores.

\section{DISCUSSION}

This study did not find an increase in eNO levels in sarcoidosis nor any relationship between eNO and the morphological extent or functional severity of disease. The data suggest that, as in other contexts, eNO levels may be higher in a subset of patients with atopy, ${ }^{13}$ but there is no evidence that sarcoidosis per se contributes to an increase in eNO. Our findings therefore confirm the observations of $\mathrm{O}^{\prime}$ Donnell et al, ${ }^{7}$ but in a much larger patient cohort and using our own population normal values for eNO. Our study did confirm our earlier observation that, in sarcoidosis, $\mathrm{FEF}_{25-75}$ and $\mathrm{FEV}_{1}$ correlate better with morphological abnormalities than other functional variables. ${ }^{14}$ However, no particular morphological pattern correlated with eNO levels.

Our results are at odds with the findings of Moodley et al ${ }^{8}$ who reported that a cohort of 12 patients with newly diagnosed sarcoidosis had higher eNO levels than 21 normal subjects. There was, in fact, no difference in eNO levels between newly diagnosed and follow up patients in our cohort. It is possible that coexistent atopy confounded the results in the study by Moodley et al and, in this regard, the decrease in eNO in eight of their patients who were treated with corticosteroids may reflect modification of atopy rather than sarcoidosis.

Exhaled NO levels are variably raised in other interstitial diseases. Higher eNO levels were reported in 47 patients with scleroderma, particularly with associated interstitial lung disease. ${ }^{15}$ In a smaller study by Paredi et al, ${ }^{16}$ eNO levels were likewise higher in patients with scleroderma associated fibrosing alveolitis $(n=17)$ and lone cryptogenic fibrosing alveolitis (CFA, $\mathrm{n}=11$ ) compared with 13 non-smoking controls. In this study the eNO levels were higher in the untreated patients and correlated with bronchoalveolar lavage (BAL) fluid lymphocyte counts. The authors postulated that the initial activation of lung inflammatory cells stimulated the production of inducible nitric oxide synthase (iNOS) which, in turn, increased production of peroxynitrite thus perpetuating the inflammatory response, citing the work of Saleh et al who demonstrated such in CFA. ${ }^{17}$ A study by Lakari et $a l^{18}$ has shown that eNO is increased in patients with scleroderma without interstitial lung disease but with increased BAL fluid cellularity. In that study, however, the patients with interstitial lung disease had similar eNO levels to normal controls. The expression of iNOS is reportedly increased in inflammatory but not fibrotic lesions in a number of interstitial lung diseases, most prominently in the granulomas of extrinisic allergic alveolitis and sarcoidosis. ${ }^{18}$ This suggests that active granulomatous inflammation may result in increased production of NO. However, in our study, patients with newly diagnosed disease were no more likely to have increased eNO levels than those under long term follow up. The data would, however, be in keeping with the observations of Moodley et al as all of their patients had acute constitutional symptoms associated with acute sarcoidosis. ${ }^{8}$ Relatively small numbers and confounding by coexistent atopy may in part explain the discrepant findings of these studies.

In conclusion, we have shown that eNO is not increased in patients with sarcoidosis although atopic patients may have raised levels. These data do not support the use of eNO to monitor disease progression in sarcoidosis as the levels do not correlate with either the HRCT appearances or the lung function tests.

\section{ACKNOWLEDGEMENTS}

The authors acknowledge the helpful advice from Associate Professor John Kolbe.

\section{Authors' affiliations}

M L Wilsher, W Fergusson, D Milne, Green Lane Respiratory Services, Auckland City Hospital, Auckland, New Zealand

A U Wells, Royal Brompton Hospital, London, UK

The chemiluminescence analyser was purchased with funds from Lottery Health Research.

Competing interests: none declared

\section{REFERENCES}

1 Moller DR. Cells and cytokines involved in the pathogenesis of sarcoidosis. Sarcoid Vasc Diffuse Lung Dis 1999;16:24-31.

2 Greene CM, Meachery G, Taggart CC, et al. Role of IL-18 in CD4+ T lymphocyte activation in sarcoidosis. J Immunol 2000;165:4718-24.

3 Taylor-Robinson AW, Liew FY, Severn A, et al. Regulation of the immune response by nitric oxide differentially produced by $T$ helper type 1 and $T$ helper type 2 cells. Eur J Immunol 1994;24:980-4.

4 Ricciardolo FLM. Multiple roles of nitric oxide in the airways. Thorax 2003;58:175-82

5 Karitonov SA, Yates D, Robbins RA, et al. Increased nitric oxide in exhaled air of asthmatic patients. Lancet 1994;343:133-5. 
6 Kharitonov SA Wells AU, O'Connor BJ, et al. Elevated levels of exhaled nitric oxide in bronchiectasis. Am J Respir Crit Care Med 1996;153:454-7.

7 O'Donnell DM, Moynihan J, Finlay G, et al. Exhaled nitric oxide and bronchoalveolar lavage nitrite/nitrate in active pulmonary sarcoidosis. Am J Respir Crit Care Med 1997:156:1892-6.

8 Moodley YP, Chetty R, Lalloo UG. Nitric oxide levels in exhaled air and inducible nitric oxide synthase immunolocalisation in pulmonary sarcoidosis. Eur Respir J 1999;14:822-7.

9 Moody A, Fergusson W, Wells AU, et al. Normal adult values, diurnal variation and repeatability of exhaled nitric oxide measurements. Respirology 1999;4(Suppl):A18

10 American Thoracic Society. Standards of spirometry. Am Rev Respir Dis 1987;136:2144-7.

11 Quanjer PH. Standardisation lung function testing. Report of working party. European Community for Coal and Steel Recommendations. Bull Eur Physiopathol Respir 1983;19(Suppl 5):1-59.

12 Roberts HR, Wells AU, Milne DG, et al. Airflow obstruction in bronchiectasis: correlation between CT features and pulmonary function tests. Thorax 2000;55:198-204.
13 Moody A, Fergusson W, Wells AU, et al. Increased nitric oxide production in the respiratory tract of asymptomatic Pacific Islanders: an association with skin prick reactivity to house dust mite. J Allergy Clin Immunol 2000;105:895-9.

14 Hansell DM, Milne D, Wilsher ML, et al. Pulmonary sarcoidosis; morphologic associations of airflow obstruction at thin section computed tomography. Radiology 1998;209:697-704

15 Moodley YP, Lalloo UG. Exhaled nitric oxide is elevated in patients with progressive systemic sclerosis without interstitial lung disease. Chest 2001:119:1449-54.

16 Paredi P, Karitonov SA, Loukides S, et al. Exhaled nitric oxide is increased in active fibrosing alveolitis. Chest 1999;115:1352-6.

17 Saleh D, Ernst P, Lim S, et al. Increased formation of the potent oxidant peroxynitrite in the airways of asthmatic patients is associated with induction of nitric oxide synthase: effect of inhaled glucocorticoid. FASEB J 1998; 12:929-37.

18 Lakari E, Soini Y, Koistinen $\mathrm{P}$, et al. Inducible nitric oxide synthase, but not xanthine oxidase, is highly expressed in interstitial pneumonias and granulomatous diseases of human lung. Am J Clin Pathol 2002;117:132-42.

\section{LUNG ALERT}

Does antibiotic treatment increase bacterial virulence in cystic fibrosis?

$\Delta$ Hoffman LR, D'Argenio DA, MacCoss MJ, et al. Aminoglycoside antibiotics induce bacterial biofilm formation. Nature 2005;436: 1171-5

B iofilm formation is an important bacterial protective mechanism that appears in the environment and clinical practice. The cystic fibrosis (CF) lung is a common model used to investigate biofilms. Recent data suggest that treatments used in CF may in part contribute to the phenotype.

This study reports that very low concentrations of aminoglycosides (including tobramycin, amikacin and streptomycin) induce biofilm formation in Pseudomonas strains, with tobramycin the most active. Thirteen of $14 \mathrm{CF}$ isolates tested formed tobramycin induced biofilms at low concentrations of this antibiotic. Biofilms were not induced by the cationic antimicrobial peptide polymyxin B, although polymyxin E (colistin) was not assessed. The induction of biofilm was not dependent on the presence of bacterial outer membrane properties such as flagellin, pili, or the alginate gene responsible for "mucoidy".

A transposon induced bank of mutant Pseudomonas strains allowed the identification of the gene responsible for tobramycin induced biofilms. The arr gene (aminoglycoside response regulator) was found to be conserved and had cyclic di-GMP (c-di-GMP) phosphodiesterase activity. Exogenous GTP (a c-di-GMP antagonist) inhibited aminoglycoside induced biofilm formation. Notably, biofilms of arr mutants were 100 times more sensitive to tobramycin in vitro. Given recent data that nebulised aminoglycoside treatment in the short term improves lung function, these new findings need to be interpreted with caution. The availability of a number of PDE inhibitors including dipyridamole and sildenafil have yet to be tested against the arr gene product and may offer a new therapeutic target.

A de-Soyza

Newcastle upon Tyne, UK; anthony.de-soyza@ncl.ac.uk 